\title{
Productivity Improvement by Applying Work Study in Kitchen of Boy's Hostel Mess
}

\author{
K.G. Padsala and J.M. Ravalji
}

\begin{abstract}
This report is an investigation of Boy's Hostel Mess problem of longer waiting time while having lunch through method study. From the analysis of existing method by Method Study, it is found that there is average waiting of 8 minutes due to Roti Making and Dish Preparation. The solution developed by critical examination of existing method, needs no any additional capital investment but a small change in existing kitchen layout. The proposed modification will result, in zero waiting time due to Roti and only one minute waiting in dish preparation.
\end{abstract}

Keywords--- Method Study, Productivity, Workplace Layout.

\section{INTRODUCTION}

$\mathrm{T}$ HE primary goal of any business or industry is to make money. The productivity is one of the measures that help to identify how well it is achieved. Productivity is a ratio of extent of output to the unit of all of the resources used to produce this output.

$$
\text { Productivity }=\frac{\text { Output Produced (Goods/Service) }}{\text { Input Expended (Men/Machine/Material/Money) }}
$$

Unlike efficiency, productivity is relative term that emphasis on increase in output with reduction of input expended [8].

Work-study is a systematic investigation tool that identifies excess work content due to faulty work methods, design of product or bad human behavior. If this excess work content can be removed by changing the existing method and that too without any additional investment, it results in productivity improvement [3].

In the beginning of investigation, the generalized problem was longer waiting time due to delay in serving and making of food in the kitchen of hostel's mess. The hostel is providing accommodation and food facility for boy students of a wellknown university in central region of Gujarat State, India. Teaching time table of the university allows a recess of half an hour (2:00-2:30 PM). On the other end, higher waiting time during lunch forces the students to skip the lunch or to have incomplete meal.Therefore, if new methods for serving or making food can be developed, students can eat satisfactorily in the given time. This paper discusses how one of the techniques of Wok Study i.e. Method Study is applied systematically to this problem and positive results are achieved.

K.G. Padsala, Student, Mechanical Engineering, Dharmsinh Desai University, Nadiad, India. E-mail:padsalakirti@ymail.com

J.M. Ravalji, Assistant Professor, Mechanical Engineering, Dharmsinh Desai University, Nadiad, India.E-mail: jmravalji.mh@ddu.ac.in DOI:10.9756/BIJIEMS.10482

\section{LITERATURE SURVEY}

Productivity can be increased in two ways: cutting down the wastes or investing more in better machines, better tooling and better workers [6].Work-study identifies and reduces the waste by reorganizing the work.

Work Study is the generic name of Method Study and Work Measurement. It was the most important basic technique in industrial engineering, which was developed based on action study of Gilberth and time study of Taylor [1]. Method Study is the systematic recording and critical examination of ways of doing things in order to make improvements. Work measurement on the other hand helps to determine the time required by the operator to complete a specified task for the defined method at the standard rate of working. Method Study is concerned with improvement in existing method for reduction in time of the work content of a job or operation [12].

For betterment of existing method, innovative steps or modifications are necessary in one or all of the following five areas that influence the performance of existing method. (1) Human activity- the hand and body motion or their sequence may be changed. (2) Work Station- a change may require in tools used, workplace layout and/or work place environment. (3) Work Sequence - the order in which workstation receive the WIP may need change. (4) Output Design-in the product design or the nature of service in case of service type output, some or complete change may require. (5) Inputs - incoming raw material may need change [7].

Method Study is performed in 8 steps as below: [3].

Step1: Select the job or process to be studied.

Step2: Record or collect all relevant data about the job or process, using the appropriate data collection techniques.

Step3: Examine the recorded facts critically considering in turn: purpose, place, sequence, person and means associated with job or process.

Step4: Develop step involves analysis of creative ideas raised by critical examination of recorded facts.

Step5: Evaluate step evaluates possible alternatives explored in Develop step against a set of specific factors such as investment required, manufacturing cycle time per unit, physical effort etc. to select optimum alternative.

Step6: Define selected improvement as the new method and the related time and present it to all those concerned, either verbally or in writing, using demonstrations.

Step7: Install the new method, training those involved, as an agreed practice with the allotted time of operation. 
Step8: Maintain the new practice by monitoring the results and comparing them with the original targets.

Many organizations have implemented Method Study in their operations and obtained positive results. In the case study of Earth Energy - a glass manufacturing company, 'mold preparation process' in manufacturing of tea cup glass was selected for Work Study. Method Study revealed that wrong location of mold room mitigate the capacity of preparing mold to 155 molds per day. By relocating the mold room near to glass shaping machine, the total time to prepare one mold could be reduced from 85 minutes to 55 minutes and capacity boosted from 155 to 237 mold per day [1].

In India, National Productivity Council had organized many projects in various industries to improve productivity and compiled their results in two volumes. In more than 13 companies, they have used Method Study to improve productivity [9].

In next section how this methodology is applied to selected problem is discussed in detail.

\section{IMPLEMENTATION OF METHOD STUDY}

\section{A. Select (Problem Definition)}

The first step in problem solving process is to select the right problem or to determine what the real problem is. The selected problem should have clear statement of purpose, goal or objective [10].

Here, in the case of hostel's mess, it is observed that the serving of food is not proper or it is not made that faster or there is delay in serving and making of food. As a result, it is difficult to serve the number of students in the given time 2:00-2:30 PM, which is recess time for the $1^{\text {st }}$ year students and students have longer waiting time while having lunch.

From the staff of mess, it is learnt that every day near about 80 students take lunch during recess time. So it is not possible to calculate waiting time for each student. Also waiting time varies day to day and student to student because of various reasons. To infer average waiting time, statistical sampling theory is used. Small no. of samples is taken randomly from large population for the purpose of study of population because of constraining factor such as cost and time [5]. As per central limit theorem, the mean of sample is considered as a mean of population [11].

Firstly, the numbers of sample that are to be drawn for study are calculated using Slovin's formula. If there is not any idea about a population's behaviour then Slovin's formula $[13]$ is used to find out the sample size.

$$
\mathrm{n}=\mathrm{N} /\left(1+\mathrm{Ne}^{\wedge} 2\right)
$$

Where; $\mathrm{n}=$ Number of samples, $\mathrm{N}=$ Total population, $\mathrm{e}=$ Margin of Error.

Now in our case, confidence level is $90 \%$ then margin of error is $10 \%$. Hence, taking $\mathbf{e}=1-0.90=0.1$ and this delay situation is for the 3 months(semester), where in a week 5 days (Monday to Friday) are there in which most of the time difficulty is found. Also, average student at mess is 80 and taking 4 weeks in a month it is found that $\mathrm{N}=3 * 4 * 5 * 80=4800$.
Therefore,

$$
\mathrm{n}=\mathrm{N} /\left(1+\mathrm{Ne}^{\wedge} 2\right)=4800 /(1+(4800 * 0.1 * 0.1))=97.95
$$

Hence, the value of $n$ (sample size) is taken as 100.With the help of five volunteer students, 100 samples are taken randomly on different days over three months of semester. In each sample, the waiting time of student during lunch is recorded along with reasons of delay. The data collection pattern is shown in table 1 . The student stands in a queue to take dish and sit on the table, then he waits until the dish is completely filled with everything such as Roti, Sabji, Rice etc. This time is recorded with symbol ' $\mathrm{D}$ '. ' $\mathrm{D}$ ' shows delay in dish preparation. When the student needs anything (like Roti, Sabji, Rice etc.) after completing the food in dish, a student has to wait and again that time is noted. Here, in the table below, ' $\mathrm{R}$ ' shows delay in Roti, ' $\mathrm{I}$ ' shows delay in Rice and ' $\mathrm{S}$ ' shows delay in Sabji.

Here only 5 readings are shown. All the other readings are taken in the same pattern on different days and five readings per day (for next 3 months).

Table 1: Readings of Waiting Time

\begin{tabular}{|l|c|l|l|}
\hline Sr. No. & \multicolumn{1}{|c|}{ Day } & \multicolumn{1}{|c|}{ Time(in seconds) } & Total time \\
\hline 1 & $10-8-2015$ & $56(\mathrm{D})+50(\mathrm{R})+80(\mathrm{I})$ & 186 \\
\hline 2 & $10-8-2015$ & $229(\mathrm{D})+183(\mathrm{R})+192(\mathrm{R})+42(\mathrm{I})$ & 646 \\
\hline 3 & $10-8-2015$ & $152(\mathrm{D})+153(\mathrm{R})+226(\mathrm{I})$ & 413 \\
\hline 4 & $10-8-2015$ & $102(\mathrm{D})+11(\mathrm{R})+41(\mathrm{R})$ & 154 \\
\hline 5 & $10-8-2015$ & $181(\mathrm{D})+149(\mathrm{R})$ & 330 \\
\hline
\end{tabular}

By calculating mean of samples, it is concluded that the average waiting time of the 100 readings is 482 seconds i.e. 8 minutes and 2 seconds. Here two way journey from class to college is about 16 minutes and waiting is about 8 minutes hence it is not feasible to eat lunch within $(30-(16+8)=) 6$ minutes. Hence, the objective of applying method study is to reduce this 8 minutes waiting time.

Further, this waiting time is due to various reasons. Pareto Analysis is used to obtain the reason presenting the greatest opportunity to reduce the waiting time [10].Pareto's law, also known as 80-20 rule uses the concept that a minority accomplishes the major part of an activity [2]. According to Pareto principle, few reasons are responsible for the major part of waiting time. Pareto analysis is done using Minitab software using information obtained from 100 samples and conclusions are made as given below.

Table 2: Pareto Analysis for Time Taken

\begin{tabular}{|l|l|l|l|l|}
\hline $\begin{array}{c}\text { Sr. } \\
\text { no. }\end{array}$ & $\begin{array}{l}\text { Reasons for } \\
\text { Delay }\end{array}$ & $\begin{array}{c}\text { Time } \\
\text { taken in } \\
\text { sec. }\end{array}$ & $\begin{array}{c}\text { Percentage } \\
\text { contribution }\end{array}$ & $\begin{array}{c}\text { Cumulative } \\
\text { Contribution }\end{array}$ \\
\hline 1 & $\begin{array}{l}\text { Dish } \\
\text { preparation }\end{array}$ & 19756 & 40.9875518 & 40.98755187 \\
\hline 2 & $\begin{array}{l}\text { Waiting for } \\
\text { Roti }\end{array}$ & 18707 & 38.8112033 & 79.79875519 \\
\hline 3 & $\begin{array}{l}\text { Waiting for } \\
\text { Rice }\end{array}$ & 9339 & 19.3755186 & 99.1742738 \\
\hline 4 & $\begin{array}{l}\text { Waiting for } \\
\text { Sabji }\end{array}$ & 398 & 0.82572614 & 100 \\
\hline Total & & 48200 & & \\
\hline
\end{tabular}




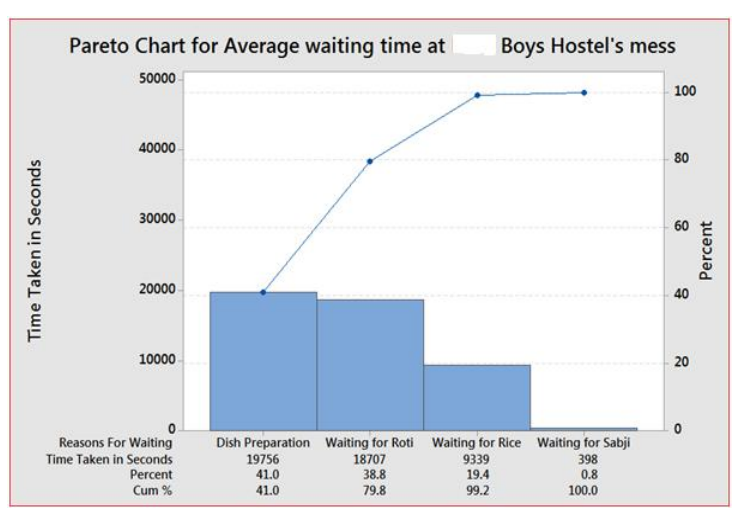

Figure 1: Pareto Chart for Average Waiting Time

From the observation of Table 2 and Figure 1, it is clear that $79.8 \%$ of average waiting time is due to two reasons dish preparation and waiting for Roti.

Table 3: Pareto Analysis for Frequency of Occurrence

\begin{tabular}{|l|l|l|l|l|}
\hline $\begin{array}{l}\text { Sr. } \\
\text { no. }\end{array}$ & $\begin{array}{l}\text { Reasons for } \\
\text { Delay }\end{array}$ & Frequency & $\begin{array}{l}\text { Percentage } \\
\text { contribution }\end{array}$ & $\begin{array}{l}\text { Cumulative } \\
\text { Contribution }\end{array}$ \\
\hline 1 & $\begin{array}{l}\text { Dish } \\
\text { preparation }\end{array}$ & 98 & 30.0613496 & 30.06134969 \\
\hline 2 & $\begin{array}{l}\text { Waiting for } \\
\text { Roti }\end{array}$ & 147 & 45.0920245 & 75.15337423 \\
\hline 3 & $\begin{array}{l}\text { Waiting for } \\
\text { Rice }\end{array}$ & 76 & 23.3128834 & 98.4662576 \\
\hline 4 & $\begin{array}{l}\text { Waiting for } \\
\text { Sabji }\end{array}$ & 5 & 1.53374233 & 100 \\
\hline Total & & 326 & & \\
\hline
\end{tabular}

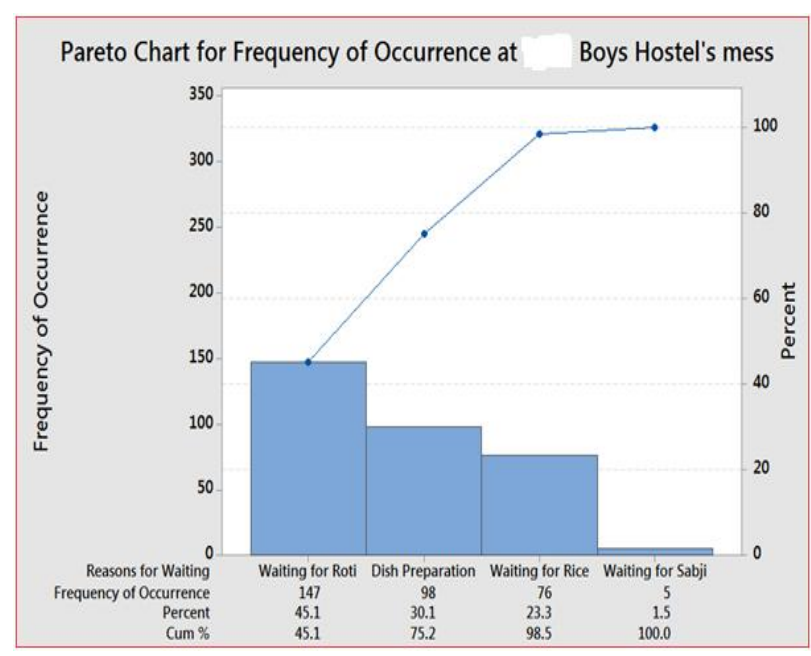

Figure 2: Pareto Chart for Frequency of Occurrence

From the observation of Table 3 and Figure 2, it is clear that waiting for Roti and Dish preparation are two reasons causing delay that has $75.2 \%$ frequency of occurrence.

Therefore, to reduce waiting time, Roti making operation in the kitchen of hostel mess is selected to apply Method Study.

\section{B. Record}

Roti Making process is recorded as shown in the Figure 3 below. Figure shows kitchen layout where Rotis are made.

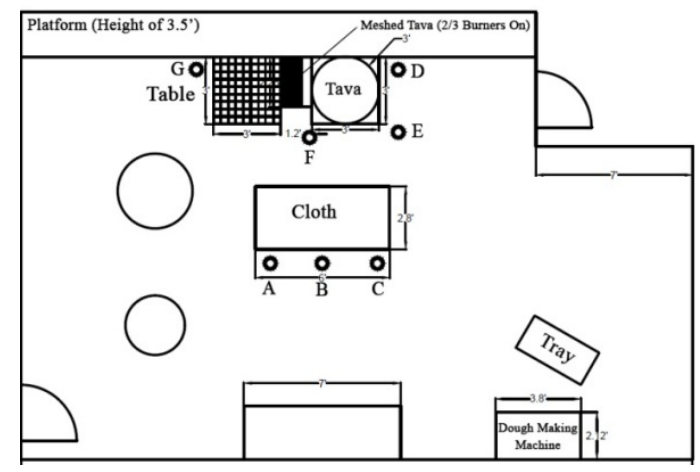

Figure 3: Current Layout of Mess's Kitchen

Here, in kitchen of mess there is dough-making machine, which makes dough $15 \mathrm{Kg}$ at a time. Then this dough is cut into smaller pieces (small dough) so that Rotis are made and put into tray which is beside it. In the figure, donut like shape shows the position of the workers.

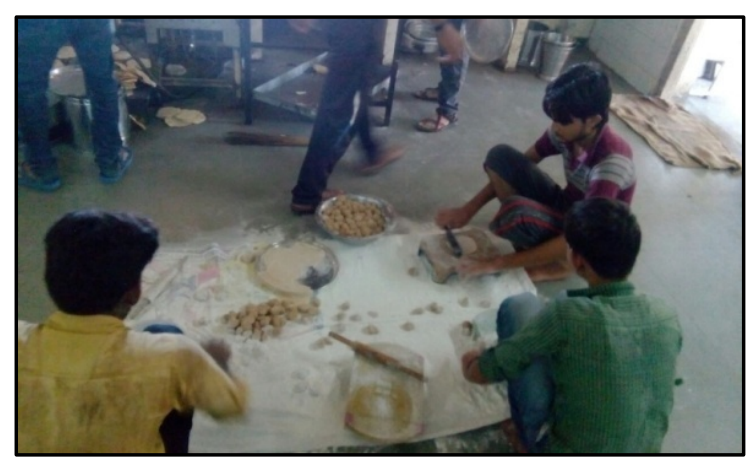

Figure 4: Layout of Existing Roti Making Process-I

Then a man comes to tray, picks up the small pieces of dough, and put them onto clean cloth, in front of three men (A, $\mathrm{B}$ and $\mathrm{C}$ are set on floor) and they will roll Rotis. Rolled Rotis will be picked up by $\mathrm{E}$ (standing) and put them on the tava.

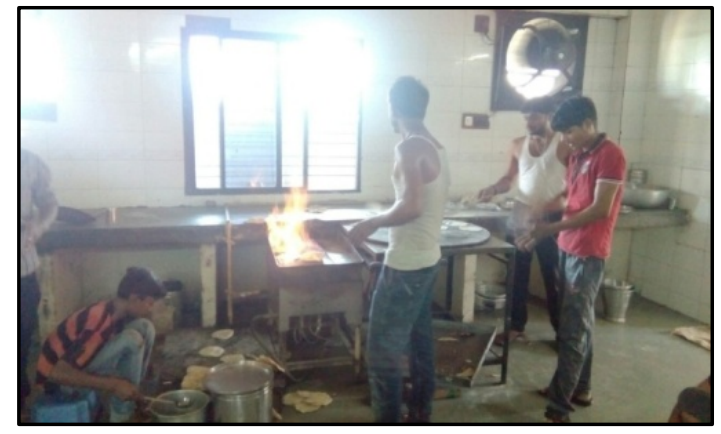

Figure 5: Layout of Existing Roti Making Process-II

Person D (standing) will rotate tava (tava is pivoted on its base so, it will rotate and tava's height is 3.5 feet) as well as he will turn Rotis upside down. Person F (standing) will be taking Rotis from tava to meshed tava (meshed tava's height is 3 feet) so that Rotis could be inflated and then $\mathrm{F}$ will put down the Rotis from meshed tava to table (height is 0.5 feet). Person $\mathrm{G}$ (set on floor) will put ghee on Rotis and collect all the Rotis. A man from entrance door will come to collect all the Rotis. Only 2 of 3 burners of meshed tava are on. 


\section{Examine}

Lunch time is 2:00 to 2:30 (30 minutes), which is divided into a group of 5 minutes for knowing arrival rate of the students.

1) From 0 to 5 minutes- 17 students

2) From 5 to 10 minutes-33 students

3) From 10 to 15 minutes-16 students

4) From 15 to 20 minutes-10 students

5) From 20 to 30 minutes - 4 students

This data is collected for the 1 month and then average is taken. Around 80 students come to mess for lunch everyday in this 30 minutes.

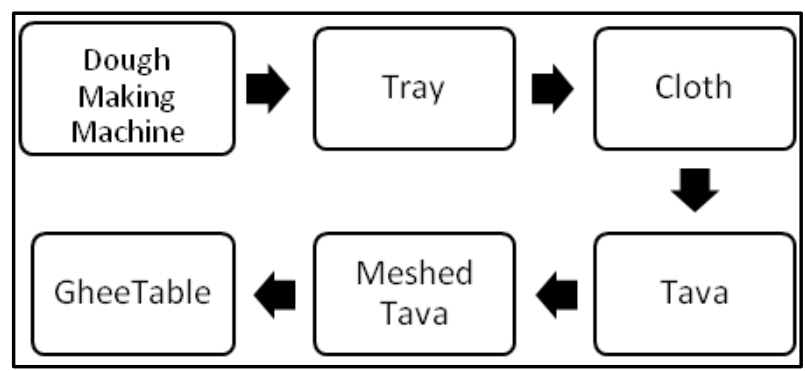

Figure 6: Bottle Neck in Process of Roti Making

Now Rotis are rolled at the rate of 30 Rotis/minute. But, person $\mathrm{G}$ put ghee on only 20 Rotis/minute. So, there is bottel neck at meshed tava. If one student eats on average 6 Rotis then there will be requirement of $(80 * 6=) 480$ Rotis. Given at the rate of 20 Rotis/minute, (30 minutes*20 Rotis/minute=) 600 Rotis could be made in given time but, according to the arrival rate in the first five minutes, demand is 102 Rotis and supply is only (20 Rotis/minute*5 minute $=$ ) 100 Rotis. There will be shortage of 2 Rotis and so on. Table 4 gives demandsupply facts for present situation at speed of 20 Rotis/minute.

Table 4: Demand-Supply Facts for Present Situation at Speed of 20 Rotis/Minute

\begin{tabular}{|l|l|l|l|}
\hline \multicolumn{1}{|c|}{ Time Interval } & Demand & Supply & \multicolumn{1}{c|}{ Shortage } \\
\hline From 0 to 5 minutes & 102 & 100 & 2 \\
\hline From 5 to 10 minutes & 198 & 100 & $98+2=100$ \\
\hline From 10 to 15 minutes & 96 & 100 & $100-4=96$ \\
\hline From 15 to 20 minutes & 60 & 100 & $-40+96=56$ \\
\hline From 20 to 30 minutes & 24 & 200 & $-176+56=-120$ \\
\hline
\end{tabular}

From the above table it is seen that demand and supply is not balanced due to the bottelneck at meshed tava. From close examine it is learnt that the roti making rate on meshed tava decreases because only 2 burners are kept on out of 3 burners. Person F is not efficient enough to work on tava and meshed tava simultaneously when 3 of 3 burners are on.

\section{Develop}

In develop step, four possible alternatives are suggested.

1) Start to make Rotis 10 minutes before the recess time and store them in casserole.

2) Re-arrangement of current layout

Re-arrangement of the current layout of kitchen could be done in the way that 3 of 3 burners of the meshed tava could be used at a time and bottleneck process could be avoided as shown in figure 4.1.

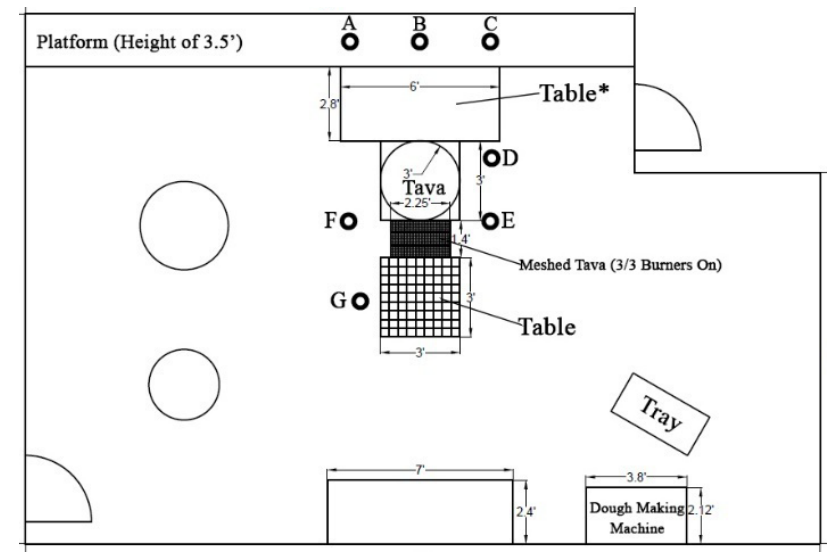

Figure 7: Proposed Layout of Mess's Kitchen

For that, as said earlier single person wouldn't been able to do work. Two person should be there for inflating Rotis on the meshed tava. Now, a table ${ }^{*}$ of height 3.5 feet is placed near platform and 3 of the person (A, B and C) are now sitting on plateform rolls Rotis. And they throw Rotis directly on the tava so that person D is free for another job. Person E does his old job of rotating tava and turning Rotis upside down. Now, person $\mathrm{D}$ and $\mathrm{F}$ will do the job of inflating Rotis and moving Rotis from tava to meshed tava. Person G collects Rotis and put ghee on them.

\section{E. Buy Automatic Roti Making Machine}

Now a days, a state of art machines are available that can make Rotis automatically. All it requires well prepared dough. It has many benefits such as less LPG Consumption, faster rate, precision in thickness and size and less manpower [4].

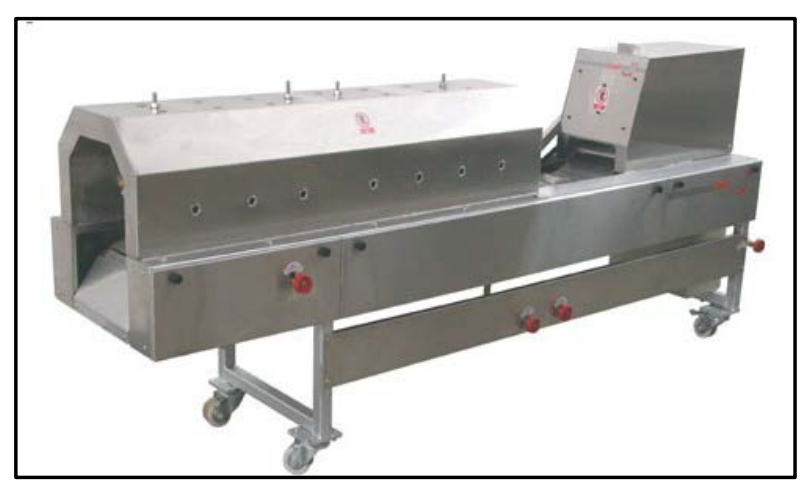

Figure 8: Automatic Roti Making Machine

1. Extending recess time from 30 minutes to 45 minutes If recess time is extended then students will have more time and they can wait for food items to be served.

\section{F. Evaluate}

In this step of Method study, developed alternatives are tested to identify the most practical and economical solution.

The cooking staff does not accept first suggestion of making Rotis in advance and storing in casserole. They have argument that Rotis in casserole sticks with each other due to Ghee applied on it. Students refuse to eat such Rotis. Secondly, some students demand hot Roti without Ghee. So to avoid waste, Roti making should start, after students arrive in mess. 
Third possible solution could be Roti making machine that is readily available in the market. Fully automatic Roti making machine available at the cost of 3.25 lacs and semi-automatic machine is available at the cost of 1.5 lacs. Both of the machine's capacity is 1000 Rotis/hour (=17Rotis/minute). Difference is just, in automatic machine Roti is made completely and in semi-automatic machine Rotis are not inflated, all the other things are done in this machine too. Both machines are available with 2000 Rotis/hour (=33 Rotis/minute capacity but at higher cost.

Out of two machines with capacity 17 Rotis/minute and 33 Rotis/minute which one should be procured is checked by balancing demand and supply of Rotis for Recess Time in Table 5 and Table 6.

Table 5: Demand-Supply Facts for Machine with Capacity of 17Rotis/Minute

\begin{tabular}{|l|l|l|l|}
\hline \multicolumn{1}{|c|}{ Time Interval } & Demand & Supply & \multicolumn{1}{c|}{ Shortage } \\
\hline From 0 to 5 minutes & 102 & 85 & 17 \\
\hline From 5 to 10 minutes & 198 & 85 & $113+17=130$ \\
\hline From 10 to 15 minutes & 96 & 85 & $11+130=141$ \\
\hline From 15 to 20 minutes & 60 & 85 & $-25+141=116$ \\
\hline From 20 to 30 minutes & 24 & 170 & $-146+116=-30$ \\
\hline
\end{tabular}

Table 6: Demand-Supply Facts for Machine with Capacity of 33Rotis/Minute

\begin{tabular}{|l|l|l|l|}
\hline \multicolumn{1}{|c|}{ Time Interval } & Demand & Supply & \multicolumn{1}{c|}{ Shortage } \\
\hline From 0 to 5 minutes & 102 & 165 & -63 \\
\hline From 5 to 10 minutes & 198 & 165 & $33-63=-30$ \\
\hline From 10 to 15 minutes & 96 & 165 & $-69-30=-99$ \\
\hline From 15 to 20 minutes & 60 & 165 & $-105-99=-204$ \\
\hline From 20 to 30 minutes & 24 & 330 & $-306-204=-510$ \\
\hline
\end{tabular}

Using machine with lesser speed, target would not be achieved and using machine with higher speed, target is achieved without shortage. But, that machine is too much costly.

Hence, the second suggestion of changing existing layout seems practical and economical. By changing sitting position of workers rolling Rotis, one worker can be spared. He can be utilized at meshed tava. As a result 3 of 3 burners can be used at a time and capacity of 30 Rotis/minute can be achieved. Doing analysis for that,

Table 7: Demand-Supply Facts for Proposed Layout with Capacity of 30Rotis/Minute

\begin{tabular}{|l|l|l|l|}
\hline Time Interval & Demand & Supply & Shortage \\
\hline From 0 to 5 minutes & 102 & 150 & -48 \\
\hline From 5 to 10 minutes & 198 & 150 & $48-48=0$ \\
\hline From 10 to 15 minutes & 96 & 150 & $-54+0=-54$ \\
\hline From 15 to 20 minutes & 60 & 150 & $-90-54=-144$ \\
\hline From 20 to 30 minutes & 24 & 300 & $-276-144=-420$ \\
\hline
\end{tabular}

In the above table, there is no shortage of Rotis. For applying change in kitchen layout only one table is required with a height of 3.5 feet which is already available in the mess. So, it will be free of cost. Target can be achieved without paying a single penny.

Fourth suggestion is to change the recess time. By stretching the recess time any further, goal can be achieved but, this needs lots of time to reschedule the entire time-table of all the courses. University management will never be ready for such change.

\section{CONCLUSION}

It is clear from evaluation step that management of hostel mess should rearrange kitchen layout for Roti making process. This modification can reduce waiting time due to Roti-making to 0 seconds which was previously 3 minutes and 7 seconds.

Second reason causing higher waiting time is Dish Preparation. Instead of waiting for food to be served in dish by serving staff, it is suggested to have a buffet system. If the buffet system is arranged the waiting time can be reduced which was previously 3 minutes and 18 seconds to approximately 60 seconds.

Now total theoretical reduction in this application of Method Study is 3 minutes and 7 seconds of Roti-making and 2 minutes and 18 seconds of dish preparation. So, total theoretical reduction in waiting time is 5 minutes and 25 seconds. Previously waiting time was 8 minutes and 2 seconds. Hence, it can be concluded that a small change in the kitchen layout can reduce waiting time for students in having lunch at Hostel's mess by $67.42 \%$. That too at zero cost.

\section{REFERENCES}

[1] C. Duran, A. Cetindere and Y.E. Aksu, "Productivity Improvement by Work and Time study Technique for Earth Energy-Glass Manufacturing Company", Procedia Economics and Finance, Elsevier Publication, Pp. 109-113, 2015.

[2] D. Herron, "Industrial Engineering Applications of Pareto's Law and ABC Curves", American Institute of Industrial Engineers Transactions, Vol. 8, No. 2, Pp. 210-218, 1976.

[3] G. Kanawaty, "Introduction to Work Study”, International Labor Office, Geneva, fourth (revised) edition, Pp. 75-168, 1994.

[4] India Mart, "chapati maker”, viewed on, 2016.

[5] J.S. Chandan, "Statistics for Business and Economics", Vikas Publication, Pp. 190-195, 2003.

[6] L.C. Jhamb, "A text book of Industrial Engineering”, Everest Publications, fifth edition, Pp. 16-30, 1998.

[7] M. E. Mundel, "Motikon and Time Study Improving Productivity", Prentice Hall Publication, fifth edition, Pp. 35-43, 1981.

[8] M. Telsang, "Industrial Engineering and Production Management", S. Chand Publication, second edition, Pp. 13-25, 2011.

[9] M. Yoga, B. Ananth Krishnanand and Rakesh Kumar, "Project Studies in Industrial Engineering”, National Productivity Council, 1974.

[10] R.M. Barnes, "Motion and Time Study Design and Measurement of Work”, Wiley Publications, seventh edition, Pp. 22-34, 1980.

[11] R. Levin and D. Rubin, "Statistics for Management", Pearson Prentice Hall Publication, seventh edition, Pp. 313-320, 2008.

[12] S. Lan, X. Wang and L. Ma, "Optimization of Assembly Line Based on Work Study”, $16^{\text {th }}$ International Conference on Industrial Engineering and Engineering Management (IEEM), Vol. 4, Pp 813-816, 2009.

[13] Statistics how to 2012, "Slovin's formula: What is it and When do I use it?", 2016. 